Laboratory of Economics and Management Sant'Anna School of Advanced Studies

Piazza Martiri della Libertà, 33 - 56127 PISA (Italy)

Tel. +39-050-883-343 Fax +39-050-883-344

Email: lem@sssup.it Web Page: http://www.lem.sssup.it

\title{
LEM
}

Working Paper Series

\section{Toward a Neo-Schumpeterian Theory of the Firm}

Sidney G. Winter

Deloitte and Touche Professor of Management,

The Wharton School of the University of Pennsylvania 


\title{
TOWARD A NEO-SCHUMPETERIAN THEORY OF THE FIRM
}

\author{
Sidney G. Winter*
}

Deloitte and Touche Professor of Management

The Wharton School of the University of Pennsylvania

Suite 2000, SH-DH, 3620 Locust Walk, Philadelphia PA 19104, USA

Winter@wharton.upenn.edu; Tel (215) 898 4140; fax (215) 8984041

March 1968 / July 2004

* Giovanni Dosi is responsible for the suggestion that this ancient, very informal paper deserved to be brought to light. Dick Nelson and other colleagues provided support for this unusual proposal (or at least shrank from opposition). Dick was much involved in the early history of the paper as well as in its recent history. For further historical insight, regarding such matters as the "cake paradigm" invoked in this paper, go to http://etss.net and click on conferences, then Nelsonfest, then "The Evolution of Dick Nelson." And then, for the Nelson version, go to http://jonescenter.wharton.upenn.edu/2003/intellectual $\% 20$ history $\% 20$ of $\% 20$ NelsonWinter.pdf 


\title{
$\underline{\text { Abstract }}$
}

\section{TOWARD A NEO-SCHUMPETERIAN THEORY OF THE FIRM}

\begin{abstract}
Sidney G. Winter
This paper offers a sketch of what an economic theory of the firm would look like if it were founded on the thought of Joseph Schumpeter, particularly on Chapters 1-2 of his Theory of Economic Development. Schumpeterian analysis requires an intuitively appealing and realistic conceptualization of the distinction between routine and innovative behavior, and in particular, a conceptualization relevant to complex organizations and complex tasks. It is argued that the production theory found in mainstream economics does not meet this requirement, particularly because its characterization of productive knowledge involves an overly sharp distinction between "technically possible" and "technically impossible" - a distinction which has no counterpart in the realities of organizational knowledge. The main elements of a Schumpeterian view are described and contrasted with those in the mainstream view.
\end{abstract}

Key words: theory of the firm, Schumpeter, innovation, knowledge. 


\title{
TOWARD A NEO-SCHUMPETERIAN THEORY OF THE FIRM ${ }^{1}$
}

\author{
Sidney G. Winter
}

\section{INTRODUCTION}

This talk is the indirect result of Burt Klein's coming to borrow my copy of Schumpeter's book, The Theory of Economic Development, a couple months ago. In the course of our comparing notes on our admiration for this book, Burt related the story that Schumpeter had taken up the study of mathematics because he believed that his theory of development would never be taken seriously by economic theorists until he could express it mathematically. I responded that Schumpeter had evidently had a very firm grasp of certain intellectual tendencies among economic theorists. I further said that my own work on the theory of the firm could be regarded as an attempt to provide a mathematical rendering of some of Schumpeter's ideas. And I was immediately signed up to give a talk on "a mathematical version of Schumpeter" or some such thing.

What I am actually going to do is to discuss the problem of converting some of the ideas in the first two chapters of The Theory of Economic Development into a coherent theory of the firm. What Schumpeter himself apparently set out to formalize was the theory of the business cycle found in the last chapter, which I consider to be less interesting. The results of Schumpeter's attempt at formalization were still less interesting. But the remarks on the firm in chapters one and two are even better than I had remembered them to be, and I am grateful to Burt for providing the stimulus that led me to look at them again. I had to look at them, of course, to determine whether my bold claims about mathematizing Schumpeter were completely crazy or only grossly exaggerated. I am happy to report that they were grossly exaggerated.

By a "theory of the firm" I mean a plausible, logically correct and complete model setting forth what are alleged to be the main determinants of the economic transactions of the firm - the quantities and prices of inputs bought and outputs sold, the amounts and interest rates involved in its borrowing and lending activities, and so forth. I assuredly do not mean a set of "laws" of firm behavior such that you could go into any particular firm and say, "Observe, the number of blue-eyed secretaries divided by the two-thirds power of the number of janitors equals 2.718 , plus or minus .001" or something like that. We are a long way from having any laws of that kind, relating to either interesting or uninteresting matters. The kind of theory I am talking about has as its main functions (a) providing guidance and structure for empirical work on firm behavior, i.e., telling the investigator what to look at, and (b) providing a framework for informed guessing about firm behavior, the kind of guessing, for

1 This paper is a slightly extended version of a talk given to a class at California Institute of Technology, October 26, 1967. It was originally circulated as a research paper of The RAND Corporation, Santa Monica, California (P-3802, March 1968). The present version differs from the original only in the deletion from the author's name of "Jr." (which he dropped in the early 1970s), the correction of some minor typos and punctuation errors, and re-drawing of the diagrams. Otherwise, this version is faithful to the original: even the bad jokes are reproduced. The opinions expressed remain those of the author - then and now, at least for the most part. 
example, that is involved in predicting haw much plant and equipment firms will buy next year.

Even with this limited objective, providing a Schumpeterian theory of the firm is a hard thing to do. The reason is that the basic ideas, when made clear, are not easily manipulated. The story told by the theory is a complicated story, and it's hard to draw any morals - i.e., to get interesting theorems out. But this is really part of the conclusion of the talk, so it is time to supply the argument.

\section{THE CONVENTIONAL THEORY: KNOWN PRODUCTION POSSIBILITIES}

To make clear the difference between the standard theory of the firm (which has been rendered mathematically in a very elegant fashion) and the theory implicit in Schumpeter's book, it will be helpful to start by recalling a very simple example of the conventional theory. Consider a competitive firm, employing a single variable input to produce a single output, within a single time period. Denote output by $\mathrm{y}$, input by $\mathrm{x}$, output price by $\mathrm{p}$, input price by $\mathrm{r}$, and let the production function be $\mathrm{f}(\mathrm{x})$. The production function, you recall, gives the maximum output that it is technically possible to produce from the given input. We assume that the firm behaves so as to maximize profit, the difference between py and rx.

For competitive firms, input and output prices are set in markets in which the individual firm's influence is negligible. Hence, of the four variables thus far identified, only $\mathrm{x}$ and $\mathrm{y}$ are to be determined within this portion of the theory. (Another theory tells us how all those p's and r's, which are given data from the point of view of each individual actor, get determined when all the individual decisions meet in the market place.) What the theory of the firm says in this simple case is: Given the function $f$ and the prices $p$ and $r$, $x$ and $y$ will be chosen so that py-rx is a maximum. Diagrammatically, we can draw $y=f(x)$ in the $(x, y)$ plane, then draw a family of straight lines of the form py-rx $=c$, where $c$ is the variable parameter. (Fig. 1) The point where the straight line corresponding to the biggest c touches $y=f(x)$ is the solution. With $f(x)$ a smooth curve, there will be equality at this point between the slope of the curve (called the marginal product of $\mathrm{x}$ ) and the slope of the line $\mathrm{y}=\mathrm{c} / \mathrm{p}+(\mathrm{r} / \mathrm{p}) \mathrm{x}$. The same conclusion could have been reached by differentiating $\mathrm{pf}(\mathrm{x})-\mathrm{rx}$ with respect to $\mathrm{x}$ and setting the derivative to zero to find the maximum.

That tells us how the firm's behavior (described by $\mathrm{x}$ and $\mathrm{y}$ ) depends on market prices ( $\mathrm{p}$ and $\mathrm{r}$ ) and technological conditions (f). The theory also yields what are called "qualitative comparative statics" results, i.e., qualitative indications of how the solution to the profit maximization problem responds to changes in the data. Suppose $(r / p)$ increases, the family of lines gets steeper, so the new solution is to the left and below the old one. (Fig. 2) Suppose it decreases; the solution moves to the right and up. This illustrates the proposition that input demand curves slope down and output supply curves slope up(assuming there is no kink of $f$ at the original solution point) .

This theory can be greatly elaborated, in the sense that we could examine the problem in the case of many inputs and outputs, in many time periods, in more general market situations, perhaps with future prices only probabilistically known, and so forth. 
To indicate the accepted path to much greater generality, let me mention the concept of a production set. For a definition of this term. we can turn to a very rigorous and sophisticated treatment of competitive theory:

"A given production $\mathrm{y}_{\mathrm{j}}$ may be technically possible or technically impossible for the $\mathrm{j}^{\text {th }}$ producer. The set $\mathrm{Y}_{\mathrm{j}}$ of all the productions possible for the $\mathrm{j}^{\text {th }}$ producer is called his production set. ${ }^{22}$

In this definition, the symbol $y_{j}$ stands for a vector in a finite dimensional vector space of arbitrary dimension. Each component of the vector represents the amount of a single closely specified commodity -closely specified in terms of date, geographical location, and all quality characteristics. Negative amounts represent inputs to the production process, positive amounts represent outputs. To relate this concept of a production set to our earlier simple example (Fig. 1), we first flip the diagram over into the second quadrant to reflect the sign convention on inputs and outputs. Then, we must note that while the production function displays the maximum output for given input, the production set includes all "technically possible" input-output combinations. The shaded region in Fig. 3 may therefore be part of the production set, if it is technically feasible to get anything less than the maximum output.

Of course, the advantage of the production set concept over the production function concept does not lie in the simple cases but in the complicated ones; the same mathematical notation provides a formal representation of an enormous range of production situations. If the point that I find objectionable about conventional theory had something to do with the number of inputs or outputs, or with the possible complexity of the intertemporal structure of production possibilities, then the simple model I started with would be a straw man, and the more powerful mathematical methods of modern theory a sufficient reply.

But "modern" theory is still in the horse and buggy stage on one crucial point; It makes a simple dichotomy between production plans that are "technically possible" and those that are "technically impossible". Within the production set, everything is known perfectly. Given a price change, the firm will move unfalteringly, instantaneously and costlessly from one profit maximum position to another. But the edge of the production set is the edge of an abyss so far as technical knowledge is concerned: We there encounter the Great Unknown. When an attempt is made to introduce the phenomenon of technological change into this conceptual scheme, the theorist is almost forced to try to play the new game by the old rules. This means that certain production possibilities are suddenly extracted from the Unknown and added to the Known. There is ordinarily no analysis as to why particular possibilities rather than others should be thus discovered, and considerations of mathematical convenience determine, by default, the path of technological development in such a theoretical world.

A more appealing, though less precise, characterization of the extent to which production possibilities are known to the firm is the following: Some possibilities are almost perfectly known, in the sense that some top manager can give an order, "Follow production plan B-17" the order will flow down through the hierarchy getting correctly interpreted and elaborated, and the firm ultimately responds in a manner very close to what the manager desired and predicted. At the other end of the spectrum, there are the things that are less than 1\% known: The president says to the director of research: "I've just been reading about the

2 Debreu, (1, p. 38) 
great strides that have been made recently in cryogenic technology. Why don't you look into that and see if there is anything that will give us a cheaper way of making popsicles." This directive is analogous to the previous one, in that both set in motion a chain or organizational events which may ultimately lead to a new set of production processes. It differs in that the timing, magnitude and character of its impact on the way the firm operates is very hard to predict. In between the two extremes there is a more or less continuous gradation of the degree to which the skills, knowledge and organizational procedures associated with a particular way of carrying on production are actually available in the firm.

Returning to our diagram of the production set (Fig. 3), let us consider a particular input level and examine the question of how the degree to which the relevant techniques are known might vary with the intended amount of output (along ac). Whereas the standard theory presents us with a cliff (at point b), we have just suggested that reality may be more closely represented by a smoothly sloping hill. Viewing the standard theory as an approximation, the approximation will be a good one if the smooth hill is very steep, less good if the slope is fairly gradual (Fig. 4).

You may feel that the notion of a production technique being $73 \%$ known to a firm is difficult to interpret in a concrete way, and furthermore, that it is not clear what use one would make of this concept in predicting the market behavior of firms. If so, I agree with you. I employ it here only to help make the point that the standard theory is simplistic in its treatment of the question of whether particular techniques are known to a firm. If possible, we should create a broader theory within which the standard theory can be viewed (correctly) as a crude approximation. Before we can proceed with the task of sketching such a theory, and showing its connection with Schumpeter's thought, we need to inquire more closely into the sense in which a firm, or any organization, "knows" how to do something.

\section{KNOWLEDGE OF TECHNIQUE: OPERATIONS AND CONCEPTS}

A distinction must be made, first, between the list of inputs and outputs associated with a production technique and the technique itself.

If the technology is that of cake baking ${ }^{3}$, the standard economics of the firm describes that technology solely in terms of the list of ingredients. Here, the "ingredients" must be understood to include no many oven-hours, so many labor-hours of the cook, as well as the eggs and flour. But "knowing how to bake a cake" is clearly not the same thing as "knowing how to bring together in one place all of the ingredients for a cake". Knowing how to bake a cake is knowing how to execute the sequence of operations that are specified, more or less closely, in a cake recipe. The list of ingredients is understood to be contained in the recipe, but the recipe is not fully revealed by the list of ingredients. The list of ingredients is, in fact, a set of summary statistics on the recipe containing just those required for economic calculation, given a set of prices for the ingredients. ${ }^{4}$

3 Cf. Nelson, Peck and Kalachek (3, pp- 8-9) on cake baking and other technologies. I should also acknowledge my indebtedness to R. R. Nelson for many productive conversations on topics related to this paper.

4 It can plausibly be argued that, for the purposes of pure theory, all of the information in a recipe can be translated into a more detailed list of ingredients. One does this (conceptually) by vastly increasing the number of commodities, admitting very fine divisions of time and 
By abstracting from all of the details in the recipe except those relevant for cost and profit calculations, the standard theory clearly effects an enormous simplification of the problem. Unfortunately, this simplification is legitimate only if the set of recipes has been clearly sorted a priori into those known to the cook and those not known. If we need to develop our own prediction of the ability of the cook to execute a new recipe, we will surely not confine our attention to the list of ingredients. We will compare all the features of the new recipe with corresponding features of ones known to be in the cook's repertoire. Baked Alaska is not just ice cream and cake, no matter how similar the ingredients.

When we attempt to discuss technology in terms of recipes, we are attempting to discuss it in terms that you could explain to a computer. A recipe describes a detailed program by which inputs can be transformed into outputs. Usually, of course, our discussion actually stays at the level of rather crude flow-charting, in which operations like "stir until thick" are represented by boxes and not analyzed further. Presumably, there is nothing essentially occult about stirring, or performing "thick-enough" tests, and with enough effort we could write out the "stir until thick" subroutine. But it is a lot easier to teach people how to do it than it is to state in detail how it is done. That this is true over vast reaches of human activity ${ }^{5}$ places definite limits on the feasibility and utility of viewing technology in terms of recipes. Those human skills that it is impossible or impractical to analyze explicitly must ultimately be treated just as ingredients - so many minutes of the services of someone who knows how to play the Paganini violin concerto. Recall, however, the point emphasized above: the detailed operations specified in recipes are crucial to the question of whether the ability to execute one list of recipes carries with it the ability to execute another, or whether extensive new learning is involved. Hence, to the extent that some of those details remain undescribed and unanalyzed, there remains a corresponding uncertainty about the ability to perform new tasks.

An even more serious limitation of the list of ingredients approach is that virtually all of the links between the technique and the totality of human knowledge are hidden from us. These links are of central importance when we are asking not about the ability to execute a given recipe, but about the ability to create the recipe from some specification of the

correspondingly many intermediate products. Thus the recipe instruction "beat the cake batter for 1 minute" gets rendered in a system in which commodities are dated at quarter-minute intervals by the sequence of input-output pairs:

$\underline{\text { Input }}$

Unbeaten butter

$15 \mathrm{sec}$. beaten batter

$30 \mathrm{sec}$. beaten batter

$45 \mathrm{sec}$. beaten batter

\section{$\underline{\text { Output }}$}

$15 \mathrm{sec}$. beaten batter

$30 \mathrm{sec}$. beaten batter

$45 \mathrm{sec}$. beaten batter

$60 \mathrm{sec}$. beaten batter

Joint products of a $15 \mathrm{sec}$. older mixing bowl and mixer appear as input and output at each stage). One then concludes that if one were confronted with a set of prices for all of the narrowly defined and dated commodities, choice of a profit maximizing vector of inputs and outputs would amount to choice of a recipe as well. For any remotely practical purpose, however, the utter absence of observable counterparts for the prices appearing in the theory will be a great handicap.

5 As emphasized by M. Polanyi (4) 
character of the output. Talented cooks can create new dishes by thinking up a new taste and then writing the recipe; talented composers can hear their music before they write down the required inputs of violin notes and horn notes; talented engineers can develop an idea about the physical basis for a new device into a detailed design. In all of these cases, the talent involved includes a sweeping grasp of the behavior of the relevant materials under a very wide range of conditions. Without actually baking the cake or playing the symphony or building the device, tentative solutions to the problem can be "tried out" and modified or rejected as necessary. There is no simple answer to the question of where this knowledge comes from. Some of it - the engineer's understanding of physical laws or the composer's understanding of harmony - is theoretical knowledge. Some of it is the fruit of long personal experience with the general class of problems involved, and some is obtained from reports of the experience of others, or direct contact with their work. Finally, the ability to perceive analogies makes possible fairly startling transfers of insight and experience from one field $d$ of knowledge or class of problems to another. How these various elements are combined and effectively manipulated in creative problem-solving is a subject on which much can be said but little is known with much certainty. ${ }^{6}$

Just to have a label, let us call this level of discussion of a technique the conceptual level as distinguished from the operational level discussed earlier. Two points should be made about it.

First, knowledge of a technique at the conceptual level can be very different from one individual or organization to another without implying any differences in input-output lists or the detailed operations. Understanding the physical principles of the technique does not necessarily carry with it an improved ability to close valves and push levers at appropriate times. When a corporation president whose experience is in finance succeeds one who started as a production engineer, the technique that the corporation is using changes even before the new president makes his first phone call: The same procedures are now embedded in a new frame of experience and analogy.

The second point is that the names of particular operations, or of whole repertories of operations, figure importantly in conceptual knowledge of a technique. Thus a phrase like "routine periodic maintenance of aircraft" can cover a large structure of fairly complicated operations and decision rules, and may be a part of the conceptual basis for a high level manager's understanding of the technique labeled "running an airline." Such a manager may have only a very vague idea of the details of maintenance activity, but he may have a very precise idea of what it has cost in the past, how that cost varies from one aircraft type to another, etc. The names of skills, occupations, or organizational units play a similar role. A rough knowledge of what a lathe operator or quality control man does accompanied by little or no knowledge of how, may form an important part of the knowledge of how to run the production department.

KNOWLEDGE OF TECHNIQUES IN COMPLEX ORGANIZATIONS

6 See ref. [2] for some interesting discussion. 
To complete the discussion of what it means for a firm to "know" a particular production possibility, we need to consider explicitly the case where the firm in question is a large and complex organization.

Each individual in such an organization is constantly engaged in receiving signals from other members of the organization or from the environment, responding to the signal with some operation from his repertoire, and thereby creating a signal for other members of the organization, or an effect in the environment. Here, the incoming signal might be the appearance of a partially finished automobile on a production line, the operation may be tightening particular screws and the outgoing "signal" is the slightly-more-finished automobile going down the line. Or' the incoming signal may be a report summarizing last month's expense account submissions from the sales force, the operation-a comparison with standards and past experience, and the outgoing signal a letter of protest. At relatively few points in most organizations do people operate with long deadlines, i.e., more than a few weeks to produce a response. Periods of minutes to hours are much more typical. At any given time, only a small number of individuals are encountering novel signals or being called upon to perform unfamiliar operations - and these are mostly people who have only recently taken on their present duties.

"Knowing your job" in such an organization is partly a matter of having the necessary repertoire of actions, and partly knowing which actions go with which incoming signals. Each individual has some ability to perform a considerably larger set of actions than are called for in his job, but to the extent that "practice makes perfect' he will acquire superior skill in the ones actually called for. [The man who graduated as a chemical engineer becomes gradually specialized first in petroleum refining and then in those particular aspects of particular refining methods that are central to his job.] As emphasized previously, a large part of any individual's conceptual understanding of his job consists of images of other peoples' jobs.

We come now to the great question: Does anybody in the large 'firm know what's going on? Answer: No. Any single individual's conceptual understanding of the firm in its entirety is mainly at an extremely abstract and aggregative level. Knowledge representing many lifetimes of education, training and experience is represented in such a conceptual picture by a few names of occupations and organizational subunits, Decades or centuries of evolution of the design of particular equipment may be represented in the firm by nothing more than a knowledge of how you work it and whom you call if it doesn't work - and even that knowledge may be limited to a few individuals. But these severe limitations on the knowledge of each participating individual do not imply that the firm does not know anything very well. For the firm to "know" a productive technique it is necessary and sufficient that each individual know his job when the firm is employing that technique. Some of those jobs relate, of course, to management information and control systems whose function is to provide incentives for individuals to perform their jobs properly, to detect and correct failures to perform, and to deal with problems posed by accidents or by ambiguities in individual roles. But only a minimal fraction of the detailed information about the technique is ever dealt with by these systems. By far the most important coordinating and organizing force is the invisible interlocking structure of mutually consistent expectations held by the various members of the organization: Each correctly expects that he will receive familiar signals from the others, and will respond in the familiar ways. 


\section{ROUTINE, ADAPTATION AND INNOVATION}

We come at last to Schumpeter's book, and in particular to his distinction between "mere managers" and entrepreneurs. In our terms, "mere managers" are people occupying managerial positions in firms operating production techniques that they (the firms) know. As Schumpeter points out, there is not much of fundamental economic interest in the distinction between such managers and the people whose activities they direct. ${ }^{7}$

It is easy to see that the characteristic of being in a higher rank, the function of superintendence in itself, constitutes no essential economic distinction. The mere circumstance that ranks one worker above another in the industrial organization, in a directing and superintending position, does not make his labor into something distinct. (p. 20)

But we see at once that the necessity of making decisions occurs in any work. No cobbler's apprentice can repair a shoe without making some resolutions and without deciding independently some question, however small.(p. 20)

...insofar as individuals in their economic conduct simply draw conclusions from known circumstances -- and that indeed is what we are here dealing with and what economics has always dealt with -- it is of no significance whether they are directing or directed.(p. 21)

The data which have governed the economic system in the past are familiar, and if they remain unchanged the system will continue in the same way. (p. 22)

In short, the manager of a firm, when the economic system is in an equilibrium circular flow, is just another guy who knows his job in a firm full of people who know their jobs.

The firm in equilibrium knows the technique it is using because it is using it, and has been for some time past.

7 Page references are to Schumpeter (5). 
...in describing the circular flow one must treat combinations of means of production (the production functions) as data, like natural possibilities, and admit only small variations at the margins, such as every individual can accomplish by adapting himself. to changes in his economic environment, without materially deviating from familiar lines. (p.81)

But,

While in the accustomed circular flow every individual can act promptly and rationally because he is sure of his ground and is supported by the conduct, as adjusted to this circular flow, of all other individuals, who in turn expect the accustomed activity from him, he cannot simply do this when he is confronted by a new task. (p.79)

This of course is where the entrepreneur comes in. The entrepreneur is the leader who leads the firm to new techniques -- in Schumpeter' terms, the "carrying out of new combinations". He makes five interpretations of this term, covering 1) new products, 2) new means of production, 3) new markets, 4) new sources of supply, 5) new organization of industry (e.g., creating a monopoly). The specific statement on new methods of production is worth quoting:

(2) The introduction of a new method of production, that is one

not yet tested by experience in the branch of manufacture

concerned, which need by no means be founded upon a discovery

scientifically new, and can also exist in a new way of handling a

product commercially. (p.66)

I am tempted to quote at length from Schumpeter's discussion of the obstacles that it is the entrepreneur's function to overcome, but will content myself with a single sentence:

Carrying out a new plan and acting according to a customary one are things as different as making a road and walking along it. (p.

85)

The general emphasis in Schumpeter's work is, of course, on the entrepreneurial phenomenon in its most pure and dramatic form, where single individuals provide the leadership needed to bring about drastically new ways of doing things. But he does occasionally (e.g., footnote, pp. 81-82) point out the essential continuity between these instances of dramatic innovation and the smallest sort of adaptation, to changing conditions.

Let us examine some of the obstacles to a "new combination" in terms of the picture of organizational knowledge developed earlier. Consider the problem of introducing a different model of a particular type of metal-working equipment into a small job-shop type of manufacturing establishment. A salesman convinces the vice president for production that his firm makes a machine which, though it is more expensive, has higher precision. The 
reduction in the number of defective parts turned out will more than pay for the added cost of the new machines.

What happens to the vice president when the new machines are installed? First of all, the rate of defective parts goes up, because the operation of the new machine is enough different from the old one that it takes some time to learn - the repertoires of action relevant to the new machine have to be learned. Defective rates are so high, in some cases, that the first batch of parts produced is in some cases not big enough, and the costs of setting up a machine to produce that part have to be incurred twice on the same job. There go the first year's profits. Secondly, the equipment maintenance man claims he just can't figure out the new machine, and the producer of the equipment has to be called in on some minor problems. Unfortunately, the legal department was unaccustomed to this sort of situation and had neglected to write into the purchase contract a provision that would make the producer carry the costs of this service. Third, it happens that Old Jack Turner, one of the five men who operates this type of equipment, is missing two fingers on his left hand. That didn't matter with the old model, but it matters with the new one. Everybody likes Jack; his job is well paid, and there is no other job around for which he is qualified and which pays anything close to his present wage. Fourth, when the higher precision promised finally materialized, it turns out that the gains are greater on some tasks than on others, and the whole question of what the defective rates are and what allowances should be made has to be restudied. And so on through a long list of hang-ups and pitfalls.

The moral of this story is not that there are overwhelming obstacles to the most modest sort of change in technique. The problems listed are not overwhelming, and our imaginary vice -president may well get them straightened out before his judgment on the original decision is called into question. The moral lies in the contrast with what happens in a second variant of the anecdote.

By chance, there occur in a single week two cases of failure to make adequate allowance for defectives when choosing the lot size. The vice president's attention is drawn to the problem posed by the defective rates and the advantages of higher precision. He decides to call in a contract research lab (recommended by his brother-in-law at a party the previous week), and poses the problem to them in the terms "there should be some way of getting better precision out of these machines."

The lab puts a good man on the problem, and he comes up with a perfectly ingenious new cutting tool for the old machines. The lab charges its customer an amount equal to two year's cost savings, and patents the device. The vice president thinks this price very high, considering that the lab only worked on the problem for a month and it has the patent to show for it. However, the firm has virtually no difficulties with the introduction of this technologically novel device. In particular, the operators of the machines and the maintenance man do not have to relearn their jobs, and the potential difficulties associated with Jack Turner's left hand are not encountered.

Moral: Sometimes an innovation involving substantial technological novelty is much less costly and difficult than a change which, by standards external to the firm, is "simple" and commonplace. Viewed from inside the firm, technological novelty is only one among several reasons why an. attempt to change techniques way involve large and unpredictable costs. 
Let me conjure up one more piece of imaginary data to support this view. Imagine that General Motors is going to get into the business of making corn flakes. We impose certain constraints on the ways they can go about it: No fair merging with General Foods, no fair buying a corn flakes factory, or hiring a. former manager or assistant manager of such a factory, or indeed anyone who has ever worked in such a factory. These constraints do not make the operation o£ a corn flakes factory any less mundane and well understood -- they merely make it difficult for General Motors to internalize that understanding. I claim that, under those constraints, the problems General Motors would encounter in this undertaking would significantly exceed those it now experiences in introducing occasional technological innovations in its existing product lines.

As Schumpeter's statement on the introduction of new methods of production suggests, the difficulties standing in the way of adaptive or innovative change have little to do with the newness of the technique in a scientific sense, or indeed in any sense that abstracts from the details of the situation in which the change occurs. They have to do with the fragmentation of relevant knowledge, both of operations and concepts, and with the degree to which some existing, functioning organization provides a solution to the problem of fitting the fragments together. ${ }^{8}$

\section{PRINCIPLES OF NEO-SCHUMPETERIAN THEORY}

The discussion so far may be concluded and summarized in a series, of related propositions constituting a neo-Schumpeterian view of firm behavior:.

(1) Contrary to the received theory of the firm, no sharp distinction can be made between techniques known to the firm and those that are unknown. There is, instead, a quite continuous gradation from highly routine behavior to highly innovative behavior.

(2) Relativity to existing routines: The only techniques which may appropriately be considered 'perfectly known' to the firm are those it is actually performing, and has been performing repetitively. Furthermore, if we revert to the metaphor of Figures 3 and 4, the steepest part of the "percent known" curve is reached very quickly as the firm departs from its existing routines. Costs and uncertainties pile up rapidly for all but the most minor departures from well worn paths - even when the new direction is one already taken by other firms.

(3) A new method o£ production is a "minor departure" from an old one to the extent that (a) the repertoires represented by the individuals currently in the firm contain the relevant skills, in roughly the right amounts, and (b) only minor "rewiring" is needed in order to create the interlocking system of signals and expectations that will evoke the appropriate actions at the appropriate times, (c) the relationship between the new technique and the old is correctly conceptualized by most individuals - so that planning for the change can go forward under largely correct premises as to who is capable of what. Similarity of lists of ingredients may be a useful proxy variable for some of these considerations, but it is not a fundamental aspect of the closeness of one technique to another.

8 They also have to do with a variety of phenomena under the general heading "vested interests in the old way of doing things", but space does not permit an exploration of that part of the problem. 
(4) Just as the fragmentation of knowledge in the firm makes innovation difficult and the consequences of attempted innovation unpredictable, no does it tend to frustrate the economist who wants to predict the lines that innovation wil1 take. As the firm gradually "learns" a new method of production, vast numbers of details of the routines established will be determined by considerations that play no part in ordinary economic calculus, and may in addition be unknown to most of the firm's managers, let alone to the observing economist. Not infrequently, decisions with quite major consequences for the firm's future economic transactions will turn on such considerations. "Mere managers" may behave predictably, entrepreneurs (and the organizations led by them) do not especially if the prognosticator directs his attention only to the economic influences on behavior.

\section{PROGRAM}

If the foregoing principles are accepted, it is clear that what is required in the theory of the firm is not a minor adjustment of existing routines, but a drastic and far-reaching innovation. The fundamental theoretical meaning of "firm" must be altered, since nothing in reality corresponds to the set of production possibilities with which each firm is mysteriously endowed as the received theory begins its story. The attributes that make the firm a significant entity, worthy of theoretical attention, are its existing patterns of routine activity, its tangible and intangible assets, its recent history, the repertoires of actions available to the individuals involved and the terms in which these individuals conceptualize the firm and their participation in it. ${ }^{9}$

As any of these attributer change, whether in response to changing prices, turnover of personnel, technological opportunities or whatever, the firm itself changes. The changes occurring in a typical firm within a typical year may be quite small, and if small they will be strongly conditioned by circumstances observable in the firm at the start of the year. They may nevertheless be fundamental; the firm's responses to given stimuli in future years will be affected. No guardian angel stands watch over the firm's identity, and a sufficiently long sequence of incremental changes can make two initially similar firms dissimilar, or two dissimilar ones converge.

To take this view, that the identity of the firm is determined by a historical process, is to abandon one very labor-saving feature of traditional theory. In that theory, the behavior of the individual competitive firm can be analyzed with prices treated parametrically, and conclusions about market prizes deduced at the end. This decomposability of the problem of price determination is lost if a firm's entire future behavior can be altered as a consequence of the values taken by market prices at a particular point of time. No analysis of equilibrium behavior is possible at the level of the individual firm. The standard conclusions of received price and allocation theory can be preserved, if at all, only as theorems describing equilibrium configurations of dynamic systems in which the histories of all the firms are jointly determined. ${ }^{10}$

9 Viewed in the framework of traditional theory, all of these attributes correspond to various sunk costs which shape the future of the firm because they lower the incremental costs of certain directions of evolution of firm routines.

10 My article (6) provides a general characterization of such systems and illustrates the possibility of obtaining traditional equilibrium results. 
Thus, a neo-Schumpeterian theory of the firm would be a historical theory in the sense that significant differences among firms would be regarded as historically determined; it would be a dynamic theory because only in the context of such a theory can the traditional problems of price theory be confronted anew, and, ideally, it would be probabilistic -- the existence of a multiplicity of unobservable factors that shape firm behavior would be explicitly recognized.

Clearly, this program is an ambitious one, involving conceptual, theoretical and empirical questions of great difficulty. Success in building a new theoretical road cannot be guaranteed, and the easier choice is to walk the old one. The question is how long we are prepared to content ourselves with a theory that is simple at the price of being simplistic. 


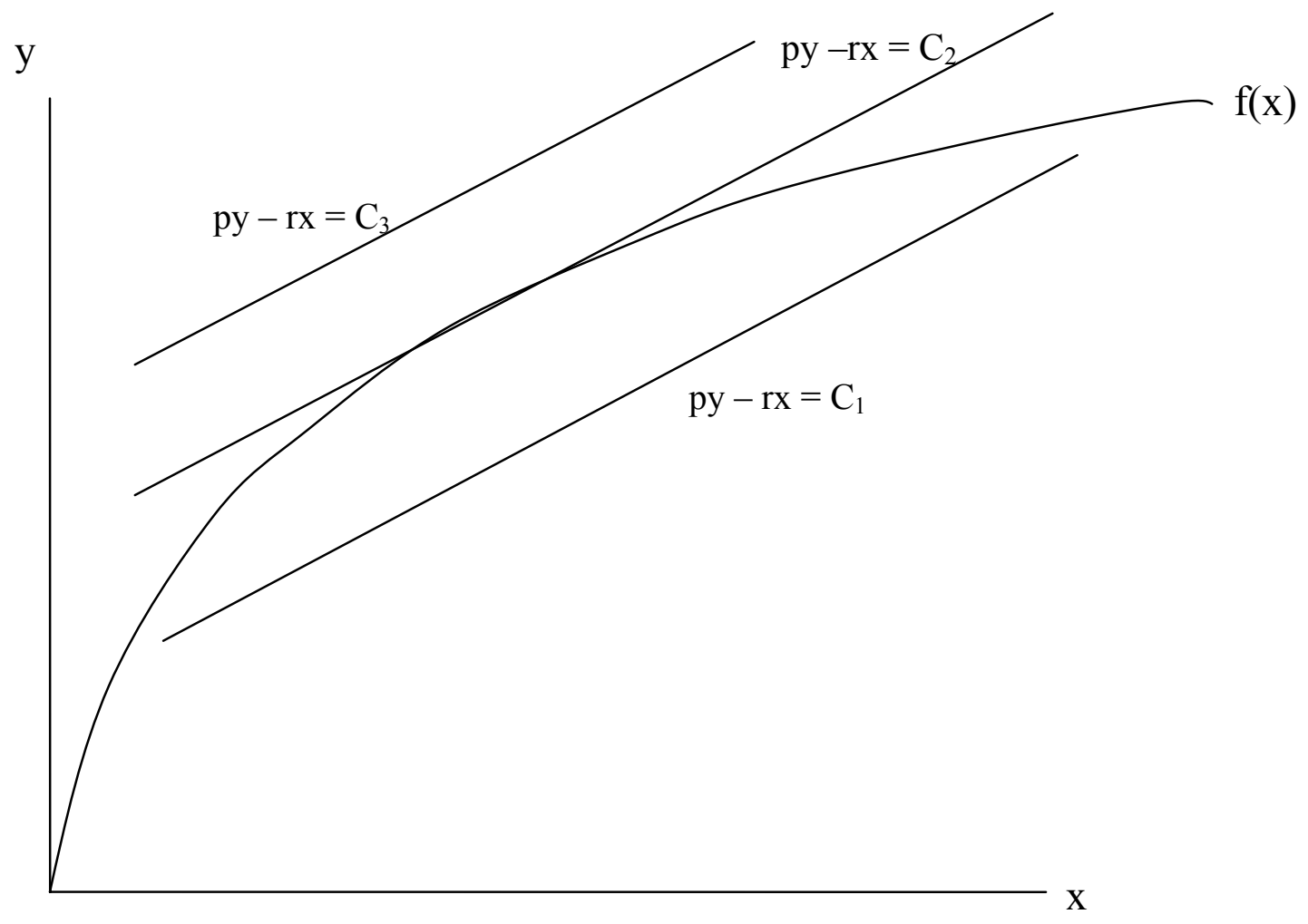

Figure 1 


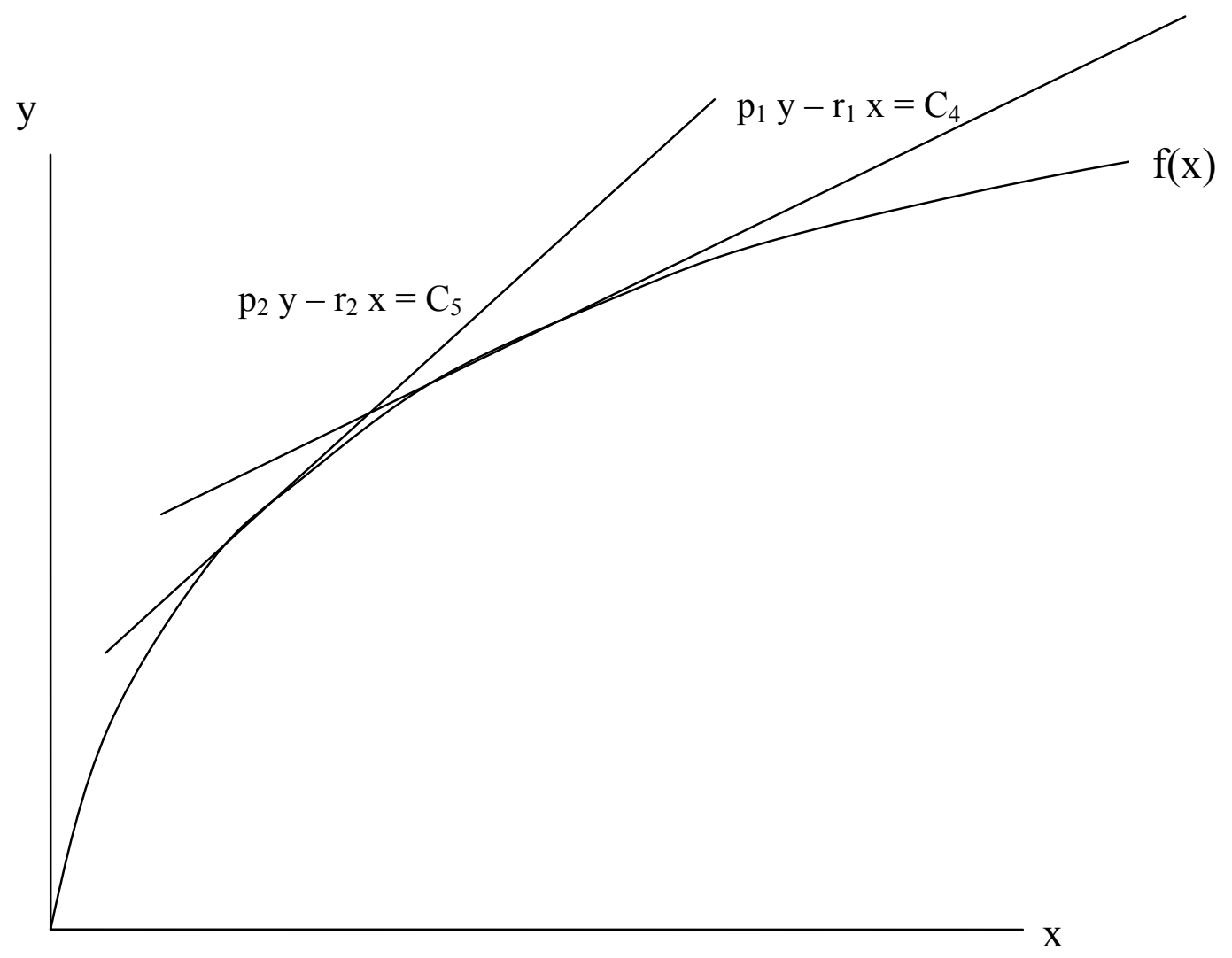

Figure 2 


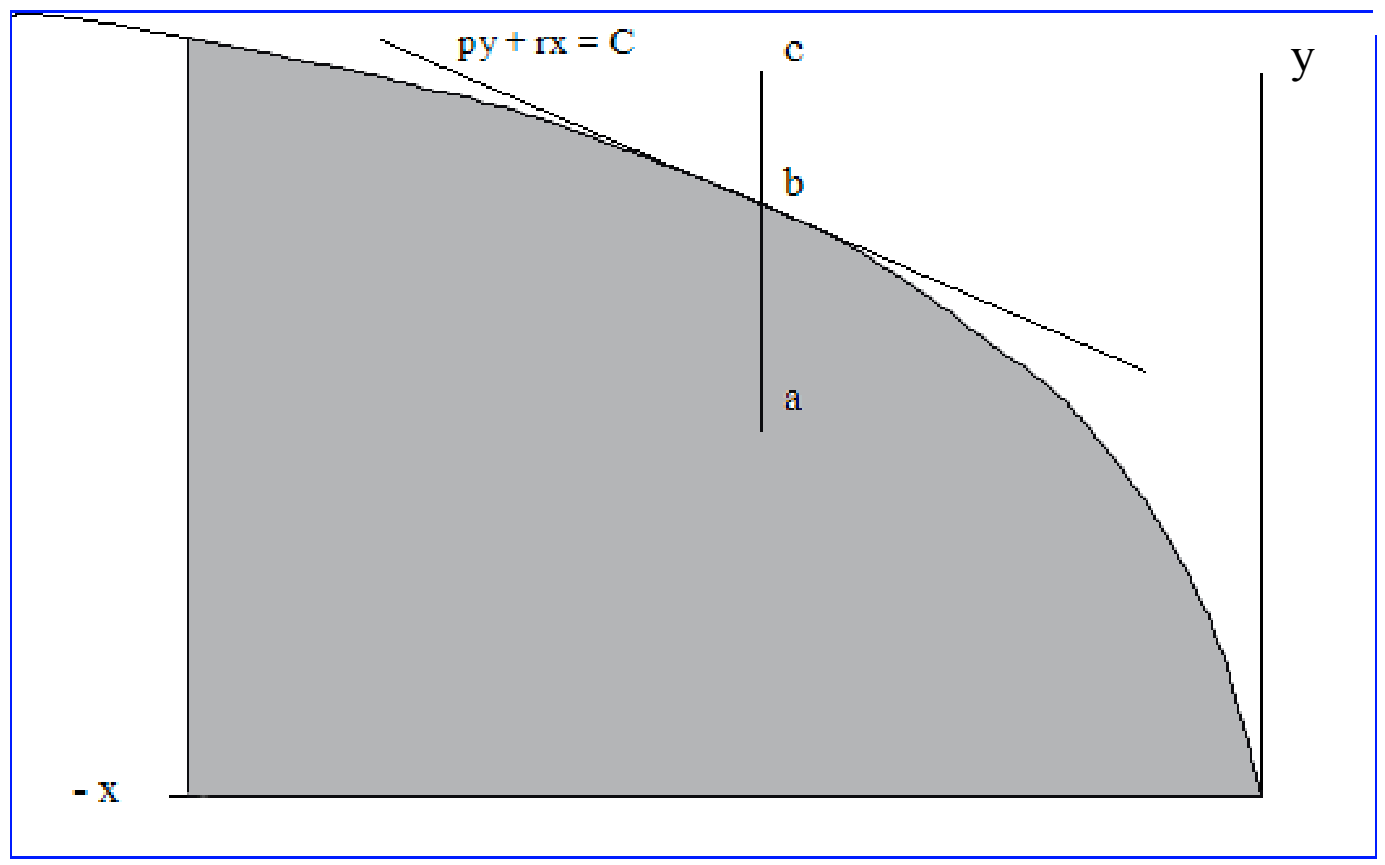

Figure 3

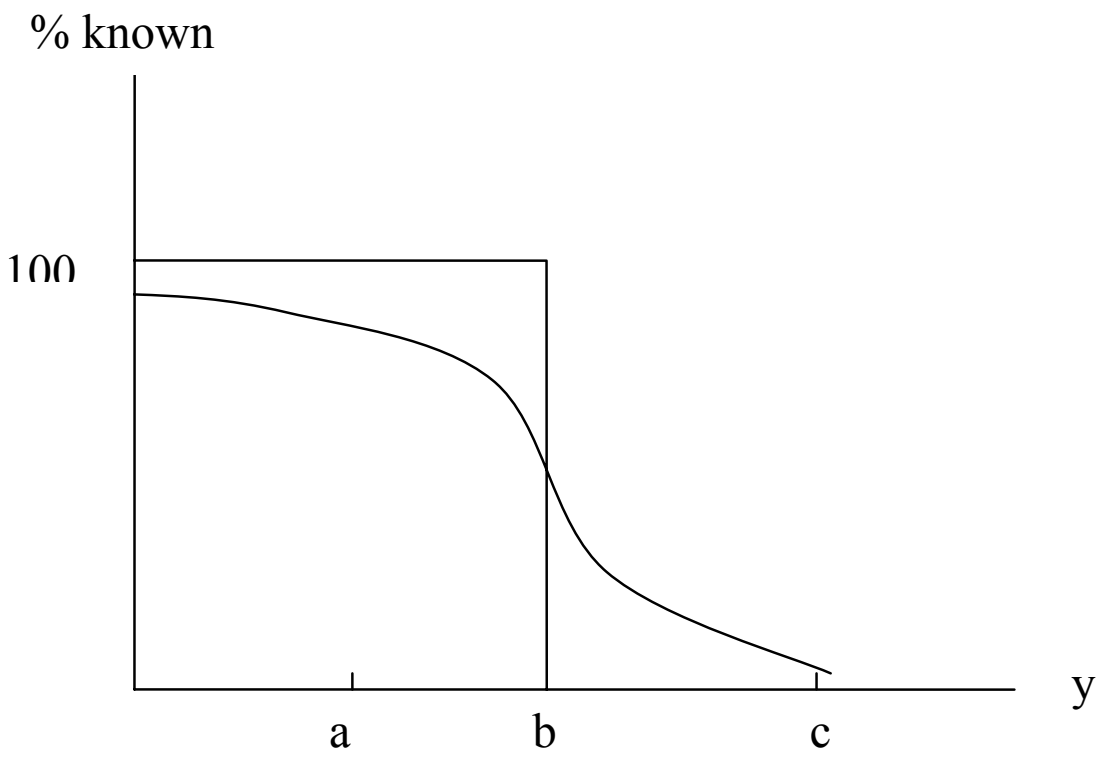

Figure 4 


\section{REFERENCES}

1. Debreu, G., Theory of Value, (New York, John Wiley and Sons, 1959).

2. Gruber, R. E., G. Terrell and H. Wertheimer, eds., Contemporary Approaches to Creative Thinking (New York, Atherton Press, 1962).

3. Nelson R. R., M. J. Peck and E. Kalachek, Technology, Economic Growth and Public Policy, (Washington, Brookings Institution, 1967).

4. Polanyi, M., Personal Knowledge, (New York, Harper and Row, 1964).

5. Schumpeter, J. A., The Theory of Economic Development, (Cambridge, Mass., Harvard University Press, 1955), first published in German, 1911.

6. Winter. S. G. "Economic 'Natural Selection' and the Theory of the Firm," Yale Economic Essays, vol. 4 (Spring 1964), pp. 225-72. 